Indexaciones: Repositorio de Revistas UCR, DIALNET, Latindex, REDALYC Directorio y recolector de recursos digitales del Ministerio de Cultura de España, Directory of Open Access Journals. Diálogos Revista Electrónica de Historia ISSN 1409-469X. Número especial 2008. Dirección web: http://historia.fcs.ucr.ac.cr/dialogos.htm

\section{Cooperativas y trabajo femenino en Guanacaste, desde la mitad del siglo XX hasta nuestros días.}

Apdo. 162120

1minwaltzman@gmail.com

Fax: 22414154

Universidad de Costa Rica

Facultad Ciencias Sociales

Escuela de Historia 


\section{Introducción}

Este es un estudio que pretende fundamentalmente, analizar a las cooperativas femeninas guanacastecas, y el desempeño del trabajo femenino, desde la mitad del siglo XX, hasta nuestros días. Enfocándonos especialmente en los años entre 1990 y el 2007. Lo que interesa, entonces, es, por un lado entender quiénes son las mujeres, para así poder comprender cómo funcionan sus cooperativas. El marco de análisis teórico del que parte este trabajo se basa principalmente, en la problemática de género. Primeramente, debemos recalcar el error, en que muchos estudios han caído, al entrar en la tendencia de "rechazar y separar". O sea, creer que la historia de las mujeres es distinta a la de los hombres y debe ser abordada por las feministas. Así mismo, se ha errado en creer que a la historia de la mujer le atañen los ámbitos biológicos (reproductivos, de la familia, entre otros) nada más. Es por esto que compartimos la apreciación, que pretende que el género sea visto de ahora en adelante, como categoría analítica ${ }^{1}$. Acercarnos a la problemática de las cooperativas femeninas, es también parte de nuestro acercamiento teórico, ya que hayamos a estas asociaciones, inmersas en un contexto cambiante, que está redefiniendo la transición de rol de género y de identidad.

Estudios explican ${ }^{2}$ algunos cambios que se dan, para finales de los ochenta y principios de los noventa, tanto en el mercado (turismo, comercio, etc.) con: el crecimiento urbano en Guanacaste, y la propagación de los servicios en centros de comercio de la región (Cañas, Santa Cruz y Liberia). Estos cambios atraen a las mujeres para emigrar hacia lo urbano, ya que la mujer 1 Scott, Joan, "El género una categoría útil para el análisis histórico", En: De mujer a género. Teoría, interpretación y práctica feminista en las ciencias sociales, Centro Editor de América Latina S.A. Buenos Aires, 1993, p 17

2 Chant, Sylvia. "Sexo Migración y estrategias de supervivencia en los hogares de bajos ingresos: en busca de las causas del crecimiento urbano de Guanacaste, Costa Rica". En: Revista Geoitsmo, vol 3, n², 1989, p96 
encontrará una amplia gama de servicios (salud, educación, etc.) a los que no tiene acceso en el ámbito rural. Las cooperativas femeninas en Guanacaste empiezan a tomar fuerza en los años setenta. Para 1980-1990, la mayoría de mujeres participa del sector terciario (producción de comestibles, y demás servicios), esto de la mano con un movimiento donde la mujer, al parecer está migrando con más potencia del ámbito rural al urbano. ${ }^{3}$ Lo que pretendemos exponer es que según Chant, las cooperativas femeninas, para finales de 1980, no pueden considerarse como la única manera de acceso al trabajo e ingresos para la mujer, ya que el desarrollo de sectores diversos en el resto de la región, atrae más fuertemente a la mano de obra femenina, a participar de otras maneras de empleo.

A parte de estas ideas, nos parece crucial insertarnos también en la polémica actual, que se propone debatir la refutable concepción, sobre la existencia de un proceso fundamental de feminización de la pobreza, el cual ha estado gestándose según algunos, desde las pasadas décadas. Apoyados en las aseveraciones de Chant ${ }^{4}$, creemos que es preciso explicitar que este estudio no parte de la aceptación de dichas teorías y busca evitar apoyar estos estereotipos, es decir, no tomamos como punto de partida la aceptación de la creencia de que estos hogares jefeados por mujeres, son los hogares más pobres entre los pobres ${ }^{5}$, en revancha buscamos enfatizar la línea ideológica que explicitan estudiosas como Chant, al decir que la creación de estereotipo sobre los hogares jefeados por mujeres, distraen la atención de las reales fuentes de pobreza, como la desventaja e inequidad de género.

Para abordar todas estas temáticas, hemos dividido el trabajo en tres capítulos. En el primero, se describe la procedencia social de las integrantes de las cooperativas femeninas.

3 Chant, Sylvia, op cit, p 103

4 Silvia Chant, "Female Headship and the Feminization of Poverty" In Focus (United Nations Development Programme), (mayo 2004): 4

$5 \quad$ Chant, "Female Headship and the Feminization of Poverty", 3 
Empezamos por tratar de conocer a las "Mujeres organizadas", es decir cuál es la base social de que están compuestas las cooperativas femeninas de Guanacaste. Indagaremos qué imágenes y percepciones del trabajo femenino, existen en las comunidades y en las propias familias de las integrantes. Para complementar esto nos preguntamos ¿debido a qué razones se crean estas percepciones?, y ¿qué influencia tienen en el trabajo de las mujeres y en sus resultados?

Posteriormente, indagamos sobre las actividades que se desarrollan en las cooperativas estudiadas, y cómo éstas se van transformando a lo largo del período de interés, como respuesta a necesidades específicas. Además, nos interesa estudiar cómo, dependiendo de las historias de éxito o fracasos, estas organizaciones consolidan o no, un rol de liderazgo en las comunidades, donde existen. Al estudiar esto se nos permitirá ver que las cooperativas, no solo poseen obstáculos de carácter económico, (en el mercado y demás instancias), si no que a su vez lideran una batalla contra las mentalidades. Finalmente, en la investigación nos detenemos, a observar la realidad actual de las cooperativas femeninas Guanacastecas. Esta realidad se funda entre dos disyuntivas, entre la realidad que viven las participantes de las cooperativas, y el Estado y sus gestiones en cuanto a legislación cooperativa. Para finalizar, evaluaremos qué está sucediendo en cuanto a los procesos de estancamiento y disolución de las cooperativas femeninas estudiadas.

Para la realización de esta investigación hemos recurrido a las fuentes orales, es decir, a las entrevistas a profundidad realizadas a ocho (8) mujeres cooperativistas, y contrastando las versiones de los actores (las posiciones oficiales, y las vivencias de las mujeres cooperativistas). Es necesario recordar, las limitaciones de utilizar fuentes orales en nuestro estudio, ya que existe una interacción subjetiva con las y los entrevistados, cuyos testimonios pueden estar cargados de distorsiones, mentiras, silencios. ${ }^{6}$.

6 Chant, "Female Headship and the Feminization of Poverty", 245 
Es preciso conocer quiénes son las mujeres cooperativistas, cuál es su entorno y de qué manera se han vinculado con el ámbito comercial, en la esfera laboral femenina del norte del país. Encontramos que la mayoría de las cooperativas son relativamente jóvenes, y que dos de ellas poseen doce (12) obreras, cantidad mínima que el Estado exige, para que estas asociaciones sean consideradas como activas. En Guanacaste, es para 1990 que la mayoría de mujeres ya participa del sector terciario (producción de comestibles, y demás servicios), lo que se refleja en las cooperativas que conocimos, por ejemplo, en el caso del sector de servicios (comidas, bienes de lujo, turismo, hasta la industria textil). La mujer se emplea cada vez más en las maquilas, las industrias manufactureras, donde soportan largas jornadas, y reciben sueldos proporcionalmente menores que el de los hombres, lo que explica su marginalidad.

Desde finales de los años ochenta, las cooperativas femeninas no pueden considerarse ${ }^{7}$, como la única manera de acceso al trabajo, que propicie ingresos para la mujer, ya que la potenciación de sectores diversos en el resto de la región, les atrae más con una mayor fuente de ingresos. Es por esto, que debe entenderse el movimiento de cooperativas femeninas, como un proceso que empieza a tomar una fuerza más consistente, para finales de la década de 1980 y a lo largo de 1990.

Las nuevas jefas de hogar deben multiplicar los escasos recursos, mientras que a nivel cultural el sacrificio viene como algo natural, y la responsabilidad del trabajo doméstico le significa una doble jornada laboral. Más y más mujeres optan por incursionar en trabajos que les reparen ingresos mucho mayores y más rápidos que una cooperativa, mientras sus situaciones continúan estancadas y sin soluciones efectivas.

7 Chant, "Female Headship and the Feminization of Poverty", 111 
Es evidente que estas asociaciones se fundamentan esencialmente con mujeres, que en su mayoría comparten dos características predominantes: ser jefas de hogar y/o las amas de casa, que se encuentran en un rango de edad de entre los 30 y los 50 años, además con estudios básicos. Otros estudios así han comprobado, un crecimiento de los índices de hogares, jefeados por mujeres en la zona norte del país. ${ }^{8}$ Las mujeres utilizan sus ingresos para destinarlo al hogar, en contraposición, los hombres tienden más a retener una mayor cantidad de ingresos para su gasto personal. Por lo tanto, este comportamiento masculino produce una gran reducción de los recursos hábiles para la casa, fomentando la existencia de escenarios, de distribución financiera y contributiva irregular, fenómeno al cual conocemos como: "pobreza secundaria". Es a la luz de estas nuevas interpretaciones, que podemos entender el crecimiento de los hogares jefeados por mujeres, ya que mientras el precio de la independencia puede ser alto para ellas, los beneficios en otras dimensiones de sus necesidades, llegan a pesar más que los costos. Así, los hogares jefeados por mujeres, pueden tener un mayor acceso a los recursos y sentirse menos vulnerables en la ausencia del control masculino.

Si indagamos más en los datos personales de las mujeres entrevistadas, podemos conocer un poco más quienes son, a qué se dedican, desde cuándo participan de estas asociaciones, y en qué se ocupan hoy en día dentro de la cooperativa. Las ocho mujeres entrevistadas, poseen la mayoría casi 10 años de trabajar e invertir tiempo en la empresa cooperativista y dicen ser amas de hogar. Además, todas ellas tienen más de 30 años de edad, en un rango hasta los 50 años de edad aproximadamente. No parece haber participación de mujeres menores de edad, salvo $8 \quad$ Sylvia Chant, "Sexo Migración y estrategias de supervivencia en los hogares de bajos ingresos: en busca de las causas del crecimiento urbano de Guanacaste, Costa Rica". Revista Geoitsmo, vol 3, n², o véase Sylvia Chant. "¿Crisis en la familia? ¿crisis en la masculinidad? Reflexiones sobre las mentalidades, el trabajo y la familia en le noroeste de Costa Rica" en Entre silencios y voces: género e historia en América Central, 1750-1990. Ed. Eugenia Rodríguez (San José. Centro Nacional para el Desarrollo y la Familia de la Mujer. 1997) 
algunos casos excepcionales. No debemos olvidar, que estas mujeres representan a un núcleo de mujeres ms amplio en cada asociación cooperativista, por lo que nuestras entrevistadas pueden servir como una muestra a escala, de la realidad más global en Guanacaste.

Doña Luz y Patricia son los únicos dos casos de mujeres que conocimos que no son jefa de hogar por si solas, si no que cuentan con sus maridos. Esto nos lleva a indagar entonces, la otra característica predominante: el ser jefas de hogar. Según Deborah, madre soltera de CoopeAmaco, su madre no estudió, puesto que ella siempre se dedicó al hogar y los hijos, por otro lado, su padre no estudió y nos dice: "lo único que aprendió [fue] a leer y a firmar". Cuatro de las ocho mujeres son madres solteras, y solo tres mujeres afirman estar casadas y compartir responsabilidades monetarias con el conyugue. Es importante preguntarnos ¿qué motivó a estas mujeres a participar de las cooperativas? Iiris, asociada de CoopeIngua en Liberia nos comenta:

“... ¿Qué le puedo decir?, aparte que eso es un beneficio para mi casa, por que tengo mi salario, tengo mi trabajo propio, trabajo para mi misma, para mis compañeras también"

La motivación del trabajo en equipo es latente, pero sin duda, la motivación número uno ha sido la remuneración el cual, se espera obtener de la cooperativa. Iiris, también de CoopeIngua, quien es madre soltera, nos relató que su propia motivación provenía del sueño de realizarse como una trabajadora, así podría proveer lo necesario para sus hijos, y ya no ser mantenida por sus padres.

En resumen, es factible afirmar que la base social de las cooperativas femeninas en

9 Entrevista hecha el día Sábado 15 de Octubre del año 2007, Liberia, Guanacaste, Costa Rica. 
Guanacaste, está formada en su mayoría por jefas de hogar y/o amas de casa, en donde proveen en algunos casos para nietos y sobrinos además de propios hijos. Estas mujeres se encuentran en un rango de 30 y 45 años de edad, y están caracterizadas por su baja escolaridad, comúnmente sin colegio, y las que han tenido acceso a este, han seguido sus estudios en los Liceos cantonales correspondientes. En su mayoría, las integrantes de las cooperativas son habitantes de barrios excluidos, y con frecuencia sus miembros se desplazan desde barrios más alejados hasta su lugar de trabajo.

Un aspecto clave a estudiar es sobre, cómo es percibido el trabajo de la mujer en su comunidad. Las mujeres no solo son afectadas por el entorno económico, sino que también deben enfrentarse contra las mentalidades y percepciones que la sociedad formula sobre ellas. Nada más en el caso de una cooperativa (CoopeIngua), estas imágenes acerca del trabajo de las mujeres han sido positivas. En el resto de los casos es nos encontraos antes desconocimiento de si hay o no algún tipo de percepción del trabajo de la mujer, es algo ya de por sí es para nosotros un indicador negativo. Varias mujeres nos dijeron que no existía alguna percepción del trabajo que ellas realizaban, mientras Doña Flor nos comento que en su familia, un ámbito donde si conocen su rol en la cooperativa, le decían seguidamente que era una "vagabunda". Por otro lado, tal y como nos relató Doña Deborah, el hecho de que los vecinos hubiesen presionado despojarlas del área que poseían para reunirse, (su "bodegón" donde tienen su taller y sus maquinas), 
apunta necesariamente a que la comunidad no cree útil el trabajo de ellas, no considerándolo importante.

En el caso del precario de Cañas, Margarita nos comentó que sus hermanos y sus familiares le llamaban lesbiana. Sus familiares le preguntaban si no le daba vergüenza dejarlos a ellos tan mal, de que ella fuera vista con "las otras lesbianas", para referirse a las otras mujeres de la cooperativa. Ella reía al contarnos esto, entonces doña Margarita nos dijo:

“...El grupo de Cañas era muy bonito: identificadas, todas unidas, trabajando juntas, se les decía que la bandera de ellas en Cañas era de homosexuales, de playos. Que pertenecían a un bando de comunismo. No podían ver la bandera de nosotras por que decían que éramos comunistas. Las veían como un grupo interno, que iban a destruir la comunidad. No era la comunidad la que las veía así, si no los políticos, la municipalidad. Eran mal vistas..." 10

Es preciso contrastar un caso completamente distinto, este es el de CoopeIngua, en donde ninguna entrevistada expresó sentir una percepción negativa de su trabajo, Iris nos comentó: "la gente me dice: te felicito por que vas a trabajar... yo tengo que venirme en la madrugada para venir aquí" y esto por que la gente conoce el esfuerzo y el éxito de la cooperativa. Entonces, ¿en qué radica entonces, la orientación de los comentarios y percepciones acerca del trabajo de las cooperativistas? Podríamos suponer, que este radica en el grado de éxito que la organización posea, y que éste tenga además repercusiones en la comunidad. Pero que exista una dinámica entre cooperativa y comunidad, tampoco es garante de una buena percepción.

Otra dimensión interesante tiene que ver con las percepciones, que las mujeres tuvieron

10 Entrevista hecha el día Sábado 22 de Septiembre del año 2007, Cañas, Guanacaste, Costa Rica. 
del trabajo femenino en las cooperativas. Deborah, de CoopeAmaco nos relataba que antes de entrar a trabajar a la asociación, se negaba a ser parte de la cooperativa. Ella cuenta que les decía a las demás mujeres:

“... ¡nombre! ¿Coser?, ¿están locas ustedes?, ¿ir ahí a quemarse el rabo, a joderse los riñones?, vea y aquí estoy quemándome el rabo y jodiéndome los riñones, como dije..." 11

Entre los estudios de Apromujer, se menciona cómo las mujeres: “...En esta dinámica se han topado con no pocos estereotipos, que tienden a reiterar la falsa creencia de que la mujer no puede desempeñar con eficiencia funciones supuestamente reservadas a los hombres..." ${ }^{12} \mathrm{De}$ hecho estas concepciones hacen eco en los estudiados mitos ideológicos de ser la femineidad, la cual crece en una sociedad que le recuerda que "ser madre es ser mujer, ... [que] ser madre es la plenitud de su feminidad..." ${ }^{13}$ Por lo tanto, se concibe que la mujer "cumple su destino al tener y criar los hijos" por que los hijos son su única misión, o la más importante. Por esto al trabajar, incursiona en un espacio ajeno, que no le atañe.

Estas concepciones se revelan como características influyentes en la dinámica laboral de las mujeres, ya que no hay una lucha tan solo a nivel comercial, si no nivel personal, en sus casas y en sus comunidades. Esto nos hace ver, cómo tanto el éxito como el fracaso de empresas como

11 Entrevista hecha el día Sábado 22 de Septiembre del año 2007, Cañas, Guanacaste, Costa Rica

12 Mireya Jiménez Guerra y Marta Campos Méndez, Diagnóstico de la participación de la Mujer en el Movimiento Cooperativo Costarricense. (APROMUJER), 1999. San José, Costa Rica), 51

13 Blanca Valladares, "Revisión técnica sobre los mitos de la maternidad" Revista Ciencias Sociales, no 65, (EUCR, San José, 1994,) 67 y 68. 
esta, se encuentran arraigados, en factores socio-culturales más profundos en la vivencia diaria del trabajo femenino.

En la dinámica de las cooperativas y su sobrevivencia, es importante el desarrollo de diversas actividades, que existan nos dice que son una clara expresión de la baja rentabilidad, que las cooperativas les deparan. Dividimos las actividades en 3 categorías: lúdicas, lucrativas y legales, y bajo cada una de ellas hemos detallado diferentes tipos de actividades realizadas.

Según lo indagado hay predominio de las actividades lucrativas. Para el caso de CoopeGuaytil, vemos dos actividades que no se han concretado, ya que son parte aún de los planes que en los últimos meses del 2007 se estarían concibiendo, para ser ejecutados tan pronto fuese posible. Es por esta razón que las hemos incluido, ya que las mujeres no las tenían tan solo como ideas, si no que ya han ido buscando la manera de desarrollarlas. En otro aspecto, estas dos actividades poseen ambas un valor representativo de la urgencia por innovar y crear, donde se conocen bien los mercados en los que trabajan y así, ellas saben qué podría potenciar las ventas de la cooperativa.

En el caso de CoopeIngua, Luz, gerente de la cooperativa, nos comentó que al estar en el centro de la ciudad de Liberia, rodeada por bancos, empresas, oficinas, la municipalidad y demás negocios, supieron que un servicio de catering para empresas sería una buena idea. Este aspecto, denota un conocimiento del mercado, además de una versatilidad necesaria, para tomar la decisión de ampliar horizontes, que como vimos cooperativas como CoopeAmaco no poseen 
en su totalidad.

En contraste, Margarita de la casi desaparecida CoopeCañas, nos decía con desanimo para qué se prestaba también el tener ingresos:

“...más bien el cinquito que nosotras llegamos a consignar, que pudimos obtener en grupo de ventas de rifas, que nos permitieron [sic] la municipalidad, nos permitieron dos ferias. Más bien los ingresos los cogimos para andar en San José, en las marchas de las grandes empresas, una fue la Dos Pinos... En el noventa y ocho, cuando querían importar leche y no los dejaban..." 14

Con el desarrollo de actividades, que buscaban diversificar (actividades económicas) las posibilidades de ingresos para las cooperativas, no se garantiza en alguna medida el éxito, por esto debe quedar en claro: la diversificación no es sinónimo de éxito. Como posibles causantes del fracaso de la estructura cooperativa, vemos la existencia de no solo, una la falta de asesoramiento, sino también una ausencia de incentivos y de capacitaciones profesionales, para el desarrollo del trabajo de la mujer. Estas capacitaciones no solo sirven para que las mujeres aprendan a gestionar los procesos y responder integralmente a las demandas locales del mercado, sino también para que se superen los obstáculos que las mentalidades presentan. Muchas de estas mujeres, temen en incursionar en otras actividades, por miedo al fracaso, habiendo una extrema sensibilidad y temor ante el riesgo, el riesgo que supone planear e invertir en una actividad nueva y por lo tanto incierta. Ante la prevalencia de estas actitudes negativas, las mujeres creen que es mejor quedarse con lo seguro, con los pocos ingresos que les dejan las actividades que si resultan exitosas. Sobre 14 Entrevista realizada el 15 de Octubre del 2007, Liberia, Guanacaste, Costa Rica 
esto Patricia comentaba completamente frustrada:

“...desde que yo entré se ha manejado la misma línea que se manejaba cuando era un taller...si se da una idea equiz no se quiere funcionar por falta de capital, por falta no se ni de qué, de miedo será o que, si es miedo digamos, miedo a que si nos va a ir bien, que si nos va a ir mal, pero para poder saber si nos va a ir bien o nos va a ir mal, hay que tirarse, hay que tirarse, $\mathrm{y}$ hasta que la mentalidad no cambie verdad, a decir bueno aventémonos, dos costos tenemos que nos vaya bien o vaya mal”15

Por eso es que creemos que no es del todo correcto decir que las actividades o la retribución de ingresos, sea el corazón de la mecánica cooperativista, ya que en la marcha, el trabajo ha revelado ser no solo fuente de sobre vivencia, si no también que de apoyo. Por lo tanto, lo que entendemos es que el éxito o fracaso en las actividades, no pueden estudiarse, sin remitirnos a la realidad emocional y abstracta que engloban las mentalidades. Es evidente que el factor del riesgo, ha sido un gran obstáculo en la vida cotidiana de las cooperativas.

A partir de nuestra investigación,${ }^{16}$ hemos visto que el sentimiento de apoyo, de solidaridad laboral, está íntimamente ligado con el éxito relativo o aparente de la cooperativa. Mientras más actividades frustradas posean las cooperativas, menos satisfacción y credibilidad en la organización tendrán las mujeres, y es por esto que se renuncia a proponer nuevas opciones, para incursionar en actividades que traigan capital extra. Pero más allá de esto, también depende

15 Entrevista realizada el 15 de Octubre del 2007, Liberia, Guanacaste, Costa Rica. 
de haber tenido la oportunidad o no, de recibir una capacitación donde se las prepare a aceptar los retos de un mercado cambiante, a moverse con la demanda e innovar con la oferta que propongan de sus propios productos, y así, de esta manera sigan captando la mayoría de beneficios.

Las asociaciones se han visto como potenciales centros de empoderamiento de líderes, propiciadores de unión de en las localidades, además de ser una vía que canaliza las necesidades expresas de las comunidades. Hemos buscado respuestas al por qué existe y ha existido siempre en las comunidades, un fuerte juego político entre las esferas de influencia, entre ellas las cooperativas. Y es que encontramos en el rol del liderazgo femenino, no solamente un arma importante para adquirir beneficios económicos, si no que por medio de éste se logra acceder a espacios de autoridad, de los cuales previamente se hallaban reservadas las mujeres. Entonces, las mujeres llegan a convertirse en potenciales demandantes de la cuota de poder, que detentan municipalidades y demás entidades regionales.

Para ejemplificar más este apartado, hemos decidido utilizar la historia de Margarita, ${ }^{17}$ la cual se refiere a lo que el liderazgo femenino puede hacer, y lo que puede estimular a través de las cooperativas. Margarita siente que ha crecido y ha adquirido superación por su vinculación con la cooperativa, pero no por beneficio implícito, si no a raíz de lo que ha aprendido en la lucha ardua. A este respecto, Margarita afirmó que:

“...yo siempre he estado por dentro de las grandes luchas y todo, para la gente soy un buen elemento, tengo bastante capacidad a través de todo lo que se me ha enseñado... [A lo que adjunta:]...tal vez algún día, tal vez les vaya a poner el ejemplo en la pura cara que es el mío propio, solita cuando saque mi diplomita y les ponga ahí la capacitación 
que yo tuve en el área empresarial... a través de mi propio negocio. Yo estoy pensando en crecer, crecer, lo primero he crecido en clientes, yo tengo mis propios clientes, tengo clientes de instituciones..." 18

Para continuar con el caso de CoopeCañas, se nos relató cómo las mujeres de la cooperativa se convirtieron en militantes de las luchas en beneficio de grandes empresas. Tal es el caso de la huelga de Dos Pinos en $1998,{ }^{19}$ a la cual las mujeres acudieron utilizando capital propio de la cooperativa, ahorrado mediante algunas actividades. ${ }^{20}$ Margarita cuenta, cómo las mujeres esperaban obtener favores y que se les abrieran puertas, al ser vistas apoyando enfáticamente la causa de la empresa, "nosotros decíamos, bueno a la par de las instituciones nosotras vamos a lograr que otra gente de allá preparada nos muestre el camino, para nosotros salir. Nunca sucedió as'í".

Entender el rol de las cooperativas ha sido fundamental para mirar estos procesos conflictivos, donde se enfrentan dos grupos (cooperativas e instituciones de toda índole) en la búsqueda de beneficios propios. Esto debe ayudarnos a ir construyendo una imagen mental de las externalidades, también las razones internas, que pueden propiciar el eventual desajuste de una cooperativa. Como afirmamos desde el principio, no podemos conformarnos con asumir el bienestar de las cooperativas, ni tampoco su decadencia, si no estudiamos lo que las aqueja, lo que necesitan para crecer, y qué relaciones crean que les sean nocivas tanto dentro como fuera de las cooperativas.

18 Entrevista realizada el 19 de Septiembre del 2007, San Pedro, San José Costa Rica.

19 Esta no es la única situación irregular, vale destacar.

20 Se cubrieron gastos de transporte, mantas y uniformes. 
Para hacer el contraste propuesto en esta investigación, tomamos las conversaciones tanto de nuestras entrevistadas, como las opiniones de Mireya, funcionaria del CENECOOP, las cuales interesantemente contrastan mucho con las palabras de las mujeres guanacastecas. Mientras Mireya nos revela la relación de hermandad que posee con los miembros, algunas de las tantas respuestas que recibimos de nuestras entrevistadas, no coinciden tanto con las de la funcionaria. Les consultamos a las entrevistadas, acerca de qué tipo de relación creen que existe entre las cooperativas y las instituciones estatales, Deborah nos comentó un suceso sumamente interesante, acerca de la presencia estatal en su cooperativa:

“...Bueno, de esta señora de las cooperativas, desde hace un año o dos que vino y no ha vuelto a venir, la señora que nos visitaba... ella nos venía animando: no dejen la cooperativa. Diay tanta hablada que nos echaba y ahora que tiene un puestecito mejor, ha subido más y nos abandonó del todo, no volvió... ¿No te acordás Flor, la señora que siempre venía? (hablando con alguien más). Doña Mireya, doña Mireya era, si, y ahora tiene un puestecito mejor ahora en San José, y ya no volvió... [Nos decía] son unas vagabundas, trabajen, trabajen más, salgan a vender...pero diay solo que "vayan a vender a otras cooperativas", le agarraba... nos hemos quedado esperando la respuesta de que "nosotros les avisamos"... Doña Mireya era como la representante allá en San 
José de las cooperativas... [Dejó de venir] desde que ya entró a toda la politiquería, por que, ay, nos vino a pedir el voto (ríe)... si hace como dos años, ahora tiene un puestecito mejor y ahora no sabemos nada de ella...ya no volvió por que se metió al lado de la política, y ahora que ganó este Oscar Arias, la metieron a ella...”21

Hablamos de la misma mujer, la que con mucho orgullo nos dijo: "Don Oscar Arias me nombró en la directiva y desde ahí estoy combatiendo la pobreza a través de la constitución de cooperativas"22. Deborah nos reitera el vínculo de Mireya con la política, lo que nos hace sospechar, que estas tienen una concepción negativa, de la asociación de esta mujer. Ella alguna vez representó aliento para ellas, ahora es representación de la persistente ausencia estatal. Para evaluar este aspecto, se ejemplifica en el siguiente cuadro, las opiniones de las mujeres las cuales, mediante una respuesta afirmativa o negativa, nos permitieron conocer quienes sienten o no el apoyo de alguna institución estatal, en la gestión de la cooperativa.

El sentimiento de una ausencia de apoyo es evidente en el Cuadro 6, en este sentido Patricia nos contesta, con una respuesta que escuchamos frecuentemente:

“...Realmente...nunca vienen verdad, ellos solamente cuando nosotros somos las que vamos allá, a dejar alguna papelería o vamos a dejar las actas, o de las asambleas, es

21 Entrevista hecha el 15 de Octubre del 2007, en Liberia, Guanacaste, Costa Rica.

22 Entrevista hecha el 06 de Septiembre del 2007, Liberia, Guanacaste, Costa Rica 
cuando como quien dice, tenemos relación con ellos..."23

Fue común encontrarnos con respuestas conciliadoras por parte de las mujeres. Algunas comentaban que quizás los funcionarios estaban muy ocupados para visitarlas, entre otras respuestas que parecían excusar la ausencia de la presencia estatal. Esta resistencia a inculpar a las instituciones por su distancia, solo puede derivarse de la ignorancia, es decir del desconocimiento de los objetivos de las instituciones estatales y su deber de estar en continua vigilancia, y dar seguimiento a las cooperativas anualmente. Bajo estas condiciones, se termina no solo en la resignación y aceptación de la situación, si no que se continúa ignorando ese deber de las instituciones. Por tal razón las mujeres no demandan que se les brinde los servicios, los cuales la institución está obligada a brindar.

De las mujeres entrevistadas, solo cinco de ocho afirman que sus problemas internos, son lo suficientemente fuertes como para reducir a la desaparición la cooperativa. Mireya por otro lado, al ser interrogada acerca de qué problemas han tenido las cooperativas femeninas en Guanacaste, nos dice sin titubear: "yo considero que ellas no tienen problema". Tan clara y llanamente, no tienen problemas. Habiendo revisado en tres capítulos la realidad social y económica de las cooperativas guanacastecas, esta afirmación se nos hace poco sostenible, infundada y puede derivarse solamente de dos posibilidades. Uno, se desconoce la realidad de las cooperativas dado a la ausencia de estudios y relaciones serias, que se dediquen a averiguar esto mismo, o dos, se le ignora adrede, para presentar un panorama positivo más ventajoso. Por otro lado, Don Jorge, consultor y asesor para varias cooperativas femeninas, nos dice al

23 Entrevista hecha el 15 de Octubre del 2007, en Liberia, Guanacaste, Costa Rica. 
preguntarle cómo ve él el panorama: "yo tengo mis dudas"24. El considera que lo que más hace falta dentro de las cooperativas, es una capacitación interna del cooperativismo en sí, que las mujeres entiendan qué es ser autogestionario, para que así, al tener claras las necesidades, sepan cómo proceder y con qué herramientas hacerlo.

Podemos por tanto, concluir que debe erradicarse la conocida reticencia de algunas instituciones estatales a cumplir a cabalidad sus objetivos y su razón de ser, recordando que su norte son las cooperativas, su bienestar y beneficio, ninguna otra instancia más que ésta.

No podemos quedarnos en conocer los puntos de vista, las bases sociales de este movimiento. Debemos necesariamente posterior a haber visto su funcionamiento, preguntarnos por qué están dando, y qué tipo de procesos de estancamiento y disolución se están viviendo. Estudiar el mercado debería ser una de las principales vertientes que debería mirarse, en él hallaremos cuáles son los retos y las trabas al desarrollo de los negocios. El caso de CoopeGuaytil nos sirve para ilustrar este punto, con la existencia de los intermediarios a la venta de las artesanías. Estos personajes liquidan las ganancias, tornándolas mínimas dado a que se llevan las piezas para venderlas a precios superiores, a lo que se les paga a las artesanas por crear las piezas. Así mismo, debe estudiarse qué precios se manejan para los productos, y qué competidores existen para los mismos.

Sin embargo, cómo ya vimos el mercado no es la única razón que apremia a las cooperativas, la ausencia de apoyo moral tanto dentro de la familia, como en la comunidad, por parte del Estado y las organizaciones, también ocasiona el desanimo de la empresa cooperativa. En este sentido a Margarita nos dice cómo dentro de CoopeCañas los ánimos se minaron por estas situaciones negativas, “...a ellas la ilusión, [para] la mayor parte [de las mujeres] de la 24 Entrevista realizada el 15 de Octubre del 2007, Liberia, Guanacaste, Costa Rica 
cooperativa, la ilusión murió...”25 Patricia nos comenta, acerca de como la situación ha afectado incluso a su familia, ya que estos no estaban:

“...Entusiasmados al principio... Qué sé yo, ya ahora de último como yo, yo siempre pienso que el estado de ánimo es imprescindible y todo se transmite, si usted está desanimada esta gente a la par suya usted la desanima... y ya en este último tiempo a mí ya CoopeAmaco a mi ya me desanimó... por lógica ya transmití ese desanimo a mi gente verdad..." 26

En otro aspecto, es importante también evaluar cuál ha sido el mayor causante de este mal estar. Es necesario indagar cuál es el principal motivo de adhesión a la cooperativa, ya que creemos que en tanto esta necesidad no es llenada por las actividades de la cooperativa, haga obligue a las mujeres a encontrar subsanar la carestía en algún otro lugar.

Podemos entender entonces que es el dinero el incentivo más importante, dado que siete de las ocho, admite haberse integrado a la cooperativa por necesidades monetarias. Escuchando lo que Luz nos dice, podemos ejemplificar este aspecto más, ella admite que: “...al principio había mucha desmotivación de las compañeras por que no habían excedentes..." ${ }^{27}$ En el exitoso caso de CoopeIngua el panorama está muy claro para Luz, la Gerente:

25 Entrevista hecha el 22 de Septiembre del 2007, en Cañas, Guanacaste, Costa Rica.

26 Entrevista hecha el 15 de Octubre del 2007, en Liberia, Guanacaste, Costa Rica.

27 Entrevista hecha el 15 de Octubre del 2007, Liberia, Guanacaste, Costa Rica 
“...En el camino hubo un montón de compañeras que se fueron y otras que llegaron creyendo en el proyecto, que son las que estamos... y nos quedamos ahí, soportamos todas los tiempos duros...yo pienso que las compañeras están bastante motivadas, es bonito, tiene sus problemas, nunca faltan en trabajos en grupo...pero si uno quiere estar ahí hay que, como decían los viejillos, hay que buscar la comba al palo...la idea de nosotros es abrir un tercer Comal cerca del parque...si ahora estamos generando 26 empleos... con otro Comal allá podíamos general tal vez 50. Podíamos favorecer a 50 mujeres y alrededor, de no sé cuantas personas, por que cada mujer tiene su núcleo que también se favorece de esto..."28

En tanto CoopeIngua hace planes para extenderse y crecer, para las demás la situación no es del todo positiva, las cooperativas están viviendo procesos de disolución. Según nos dice Mireya, “...Es decisión de la gente de las comunidades, nosotros ya no podemos, si quisieron ${ }^{29}$ deshacerse y no quisieron seguir más es cuestión de ellos... nosotros tratamos de ayudar, pero si vemos que del todo no se puede, entonces se disuelve..." ${ }^{30}$ Patricia nos dice: “...mi persona, ya no quiero acompañar este proceso, porque yo no veo cambio..."31

La realidad inmediata que están viviendo estas asociaciones, es la constitución de asambleas las cuales se estarían celebrando en los últimos meses del 2007. En estos espacios se buscará

28 Entrevista hecha el 15 de Octubre del 2007, Liberia, Guanacaste, Costa Rica.

29 La itálica es de nosotras

30 Entrevista hecha el 19 Septiembre del 2007, en Liberia, Guanacaste, Costa Rica

31 Entrevista hecha el 15 de Octubre del 2007, en Liberia, Guanacaste, Costa Rica. 
tomar decisiones acerca de si permanecer activas o no. Se involucran dos ópticas particulares en la toma de decisiones, o sea estos procesos de desintegración atañen dimensiones que repercuten en la comunidad, más allá también en lo personal de las mujeres, en sus hogares. Mientras los encargados se no parecen estar haciendo lo necesario para preservar a las cooperativas, como espacios de sana producción y repartición justa, más y más cooperativas femeninas sufren de sus vidas efímeras, aisladas, sin guía.

\section{Conclusiones}

Primordialmente, el cooperativismo busca fomentar la intervención estatal, que garantice recursos y personal, para fortalecer integralmente a las cooperativas en todo el país. Pero hoy por hoy, habiéndose agotado casi irreversiblemente el modelo interventor del siglo pasado, nos hayamos en la nueva lógica del Estado. Esta promulga la propiedad privada a toda costa, la reducción del aparato estatal, donde es normal que los presupuestos para sus instituciones estatales, (como las encargadas del cuido de todas las cooperativas), se recorten con más asiduidad. Por otro lado la privatización de la banca liquida bonos y préstamos, para la asistencia y la financiación de la pequeña empresa y la micro empresa. Ninguna de las razones indagadas en nuestro estudio, por más importantes que fuesen, parece ser más relevante que el golpe que se le da al sector cooperativo, a raíz de la crisis del modelo de desarrollo nacional y equitativo. Ya que la razón de ser de estas organizaciones, fluye de las políticas que el Estado dicta sobre la legislación y el mercado.

En nuestro estudio nos hemos encontrado con 4 cooperativas, con mujeres muy iguales, 
en realidades desiguales. Por los vicios tanto internos como externos de estas cooperativas, la mayoría de ellas se haya en procesos de estancamiento, y algunas más desafortunada en desintegración. Al comenzar con esta investigación, propusimos diversas hipótesis, dijimos que las cooperativas permiten la presencia de mujeres de los bajos estratos sociales, con una mayoría de jefas de hogar y/o amas de casa al mando de sus hogares, como su base social, en un rango de edad entre 30 y 50 años. Además estas mujeres, se caracterizan por poseer una baja escolaridad, en su mayoría poseen estudios primarios, inconclusos. Es posible constatar que estas ideas de hecho se confirmaron en nuestro análisis. Estas mujeres, han buscado en las cooperativas una manera de obtener ingresos en labores técnicas, por que no han cursado algún tipo de estudios especializados. Además de su trabajo, ellas poseen la responsabilidad del trabajo doméstico que les significa una doble jornada laboral. En cuanto a las mentalidades y las percepciones del trabajo femenino, la mala concepción y la desconfianza para con la cooperativa, hace que las mujeres no sienten el apoyo de la comunidad, y familiares. Lo más valioso de estas conclusiones, es que nos sirve como indicador, del tipo de procesos negativos y debilitantes, que se han estado gestando alrededor de las cooperativas.

Encontramos tres actividades básicas en la cotidianeidad de las cooperativas: las lúdicas, lucrativas y puramente legales. Las legales, las lúdicas que buscan recrear al grupo, mas sin embargo, la necesidad de obtener ingresos, tanto para los salarios, como para realizar inversiones en la producción, hacen más necesarias aún, a las actividades lucrativas. Es más importante señalar a partir de esto, que la comunidad y las mismas mujeres, evaluarán su desempeño con base en el fracaso, o el éxito que obtengan de las actividades. Los éxitos harán que la organización sea vista con confianza, de lo contrario la población desconfiará de la empresa cooperativa. Hemos encontrado, que el miedo a la incursión, la conciencia de riesgo que poseen las mujeres, 
y la ausencia de credibilidad tanto en la cooperativa como en sí mismas que experimentan, perjudican el desempeño de las cooperativas.

Este estudio nos han llevado a ver los procesos de consolidación del liderazgo femenino, y cómo a su vez las cooperativas han sido parte de los juegos políticos y de poder, que crean fricciones de intereses en las comunidades. Tanto las cooperativas como las instituciones, buscan beneficiarse la una de la otra, más la mayoría de las cooperativas no han experimentado más que situaciones irregulares, sin verse beneficiadas en estos juegos de poder. Existen, por esto más allá de problemas económicos y técnicos, relaciones nocivas (o positivas) dentro y/o fuera de las cooperativas, que pueden beneficiar a las asociaciones, o por el contrario, seguir presentándose como un obstáculo para su desarrollo. Solo estudiando cómo estas situaciones evolucionan, cómo las necesidades de las cooperativas han evolucionada también, es que podremos presentar, nuevas respuestas que posibiliten terminar con los problemas desde su origen, y permitan creer un futuro prometedor para las cooperativas femeninas guanacastecas.

Finalmente, creemos que los beneficios que las cooperativas han obtenido han sido escasos, más bien al cabo de los años, estas se han estancado. Sea esto, por falta de mano de obra para suplir demanda, por la ausencia de la guía estatal, o por conflictos internos en las comunidades que involucran situaciones irregulares. Algunas capacitaciones facilitaron herramientas a algunas de estas mujeres, para aprender a negociar, administrar la confección y venta de sus productos, buscando con más astucia a sus clientes. Aún así las cooperativas han debido acomodarse, a los bajos precios que se les ofrece por sus productos. De acuerdo con lo expuesto en el último apartado, las opiniones tanto oficiales como de las mujeres, nos ha hecho evidente algunas divergencias.

El problema no es tanto la disyuntiva per se, si no que es la ineficacia de aquellos 
organismos responsables de dar respuesta, de apoyar a las cooperativas. Un problema es también, que no hay seguimiento de estos estudios sobre las organizaciones femeninas. Mucho menos hay seguimiento de cerca con estas mujeres, ya que qué mejores informantes, que estas mujeres, que saben lo que viven y necesitan ${ }^{32}$. No hemos encontrado un sistemático y persistente esfuerzo cambiar esta realidad por parte de ninguna institución. El desanimo y la conciencia de riesgo, atan a las mujeres a una situación persistente de resultados negativos, mientras en el otro la falta de recursos, de estudios, y de decisiones más firmes perpetúan estos problemas. No se proponen cambios radicales en legislación, en administración y en el compromiso de ambas partes, tanto mujeres como instituciones. Es de todos modos, prometedor ver en este ámbito, del género y la sociedad, como categorías vacías y ricas, vacías por que no poseen un sentido último vital y ricas por que aunque parecen estáticas y rígidas contienen muchos matices diversos y reprimidos, que aún pueden ser y deben ser abordados por las ciencias sociales.

32 En el Congreso de Autogestión del CICOPA, para Agosto del 2006 en San José, participaron diversos integrantes de cooperativas guanacastecas, en las mesas de trabajo de la región Central, Limón y Guanacaste. Las cooperativas dijeron poseer como debilidades la falta de capacitación en la gestión e identidad cooperativa, una ausencia de financiamiento accesible y diferenciado, más una carencia de normas laborales y de seguridad social. Finalmente, al referirse a las amenazas, estas apuntaron a la existencia de una tendencia a no generar políticas públicas. 